DOI: 10.12731/2227-930X-2017-4-9-25

УДК 622.28.001

\title{
АНАЛИЗ НАПРЯЖЕННО-ДЕФОРМИРОВАННОГО СОСТОЯНИЯ МОНОЛИТНОЙ БЕТОННОЙ КРЕПИ ПОДЗЕМНЫХ СООРУЖЕНИЙ НЕКРУГОВОГО ОЧЕРТАНИЯ
}

\author{
Бауэр М.A.
}

Приведены результаты исследований напряженно-деформированного состояния (НДС) крепи и грунтового массива подземных сооружений некругового очертания глубиной заложения до 50 м в неустойчивых наносных породах с заходками от 0,3 до 0,7 м. Исследование выполнено путём моделирования НДС массива грунта и твердеющего бетона монолитной крепи, возведенной вслед за подвиганием забоя.

Для реализащии предлагаемых технологических решений обеспечивающих крепление подземных сооружений монолитным бетоном для исключения применения временной крепи требуется использование особобыстротвердеющих составов. На основании исследований ряда модификаторов установлены изменения механических свойств наиболее эффективных составов, которые использованы для моделирования бетонной крепи сооружений с изменяющимися во времени характеристиками.

Цель: обоснование ресурсосберегающей технологии строительства подземных сооружений некругового очертания в грунтовом массиве.

Метод или методология проведения работы: исследования проведены методом конечных элементов (МКЭ) с использованием оптимального планирования эксперимента.

Результаты: получены распределения напряжений в твердеющей бетонной крепи сооружений, установлены зоны концентрациии напряжений, установлены величины смещчений в грунтовом массиве и их распространение на поверхности. 
Область применения результатов: результаты исследований могут применяться при проектировании вариантов строительства подземных сооружений.

Ключевые слова: прохождение; крепление; прочность бетона; напряжения; моделирование; план эксперимента; смещения.

\section{THE ANALYSIS OF INTENSE-DEFORMED MONOLITHIC CONCRETE STRIP STATE OF UNDERGROUND STRUCTURES OF NONCIRCULAR OUTLINE}

\section{Bauer M.A.}

The research results of intense deformed state (IDS) of the crepe and soil massif of un-derground structures having a non-circular outline with a depth of laying up to $50 \mathrm{~m}$ in unstable al-luvial rocks with dumps from 0.3 to $0.7 \mathrm{~m}$ are presented. The study was carried out by means of modeling the IDS of the soil massif and the hardening concrete of the monolithic support, erected after slaughter moving. To implement the proposed technological solutions ensuring the fixing of underground structures with monolithic concrete, it is necessary to use particularly fast solidifying compounds to exclude the use of temporary crepe. Based on the studies of a number of modifiers, various changes in mechanical properties of the most effective compositions have been established, which are used to simulate the concrete crepe of structures with time-varying characteristics.

Purpose: the basis for using resource-saving technology for the construction of underground structures in a non-circular outline in a soil massif.

Methods and methodology of the work: the studies were carried out by means of the finite element method (FEM) using the optimal design of the experiment.

Results: stress distributions were obtained in the hardening concrete crepe structures, stress concentration zones were established, 
displacement values in the soil massif and their spread on the surface were recieved.

Areas of the result application: the results of research work can be used in the design of options for the construction of underground structures.

Keywords: passage; fixing; strength of concrete; stress; simulation; experimental design; displacement.

\section{Введение}

Тенденция к увеличению объемов строительства подземных объектов во всем мире сохраняется на протяжении десятилетий, как в крупных городах, так и в других регионах. Это обусловлено тем, что подземное строительство имеет огромное значение для надежного функционирования городской среды и систем жизнеобеспечения, также позволяет сохранить уникальный внешний облик центральных районов городов, их ландшафты и целые природные комплексы [1-3].

Использование подземного пространства для размещения объектов различного назначения, помимо повышения эффективности использования недр, экономии территории и сохранения экологической чистоты, уменьшает затраты энергии на отопление и охлаждение помещений, сокращает эксплуатационные расходы по сравнению с расходами на альтернативные сооружения на поверхности, снижает влияние климатических условий [1].

В настоящее время строительство подземных объектов различного назначения во всем мире становится одним из приоритетных направлений. За последнее десятилетие на юге России в районе городов Сочи, Новороссийск, Дивноморск, Туапсе и Ростова-на-Дону осуществлялось строительство в наносах более двух десятков объектов. Реализация планируемого на ближайшие годы развития транспортной системы крупных городов России также будет способствовать увеличению объемов подземного строительства. Таким образом, масштабы строительства подземных объектов с каждым годом будут расти. 
Освоение подземного пространства сопряжено с ростом объемов проходки выработок в неустойчивых наносных породах, о чем свидетельствует опыт строительства в России и многих зарубежных странах.

Для проведения протяженных выработок используются высокопроизводительные механизированные комплексы, обеспечивающие высокую скорость проходки. Однако при строительстве подземных сооружений небольшой протяженности (устья наклонных стволов, врезки тоннелей различного назначения, подземные переходы, эскалаторные ходки, вентиляционные и технологические сбойки перегонных тоннелей) применение таких комплексов невозможно. В этом случае большинство подземных сооружений в грунтах проводится с применением временной крепи, что сопровождается существенным увеличением затрат на возведение объектов.

\section{Состояние вопроса}

Отсутствие эффективных средств механизации для проведения выработок небольшой протяженности и специфические особенности наносных горных пород (малая прочность и значительные смещения без нарушения сплошности массива) обуславливают, как правило, применение высокозатратных технологий прохождения и крепления. Разработанные к настоящему времени методы и средства строительства подземных сооружений практически в любых грунтовых условиях, также требуют дополнительных затрат.

При проходке тоннелей в условиях плотной городской застройки при небольшой глубине заложения формируется процесс сдвижения грунтов и оседания поверхности, что существенно осложняет эксплуатацию зданий и сооружений на поверхности, расположенных над тоннелем. Это обусловлено тем, что существующая технология предусматривает наличие зазора между тюбинговой крепью и стенками массива [4]. После возведения крепи зазор заполняется тампонажным составом, однако в большинстве случаев смещения грунта в своде происходят до нагнетания. Это приводит к проседанию поверхности земли до 45 мм [5]. 
С увеличением глубины заложения сооружения проседание пород и зоны мульды оседания уменьшается, но при этом развитие мульды сдвижения земной поверхности может захватывать целые микрорайоны застройки [5]. Сократить величину деформаций поверхности можно увеличением давления нагнетания, однако этот процесс также не лишён серьезных недостатков [6].

Минимизировать такие негативные явления можно при креплении подземных сооружений монолитным бетоном, что исключает наличие технологического зазора. Однако монолитный бетон, характеризуется отсутствием требуемой прочности в течение длительного срока после укладки за опалубку. Поэтому требуется возведение временной крепи для предотвращения обрушений грунтовых обнажений. В этом случае затраты на строительство подземных сооружений существенно возрастают.

Снизить смещения пород и соответственно вероятность обрушения незакрепленного массива при строительстве выработок в грунтах можно уменьшением величины заходки до 0,3-0,7 м, что позволит минимизировать пластические деформации контура выработки и исключить обрушения незакрепленного массива связных грунтов. Крепление быстротвердеющим монолитным бетоном сразу за обнажением пород существенно снизит стоимость, продолжительность, трудоёмкость и материалоёмкость работ [7]. Применение такой технологии требует детальных исследований модифицированных бетонов. На основе анализа свойств бетонов для возведения крепи подземных сооружений $[8,9]$ и влияния модификаторов на кинетику структурообразования [10, 11], определены наиболее эффективные составы [12].

Детальные исследования скорости набора прочности модифицированных бетонов позволяют определять несущую способность бетонной крепи сооружений в различные сроки твердения. Аналитические решения по определению НДС геомеханических систем очень сложны. Поскольку в данном случае необходимо рассчитывать НДС грунтового массива и упрочняющейся во времени крепи, то трудоемкость задачи возрастает многократно. 
В настоящее время для оценки взаимодействия грунтового массива и строительных конструкций широко применяется метод конечных элементов [13-15], отличающийся простотой и хорошей сходимостью с результатами натурных исследований $[16,17]$. Поэтому большинство исследователей при оценке НДС сложных геомеханических систем отдают предпочтение моделированию МКЭ. На основании имеющегося опыта автором проведена оценка напряженно-деформированного состояния (НДС) массива грунта при уменьшении длины заходки путем трехмерного моделирования МКЭ выработки кругового очертания [7]. Для этого, на моделях с одинаковыми характеристиками массива пород, подземного сооружения и крепи, исследован характер распределения величин напряжений и деформаций по продольной оси выработки.

Анализируя распределение напряжений в нетронутом массиве на расстоянии 0,6 м от забоя можно было установлено, что число узлов с напряжениями, близкими к предельным в моделях с заходкой 1,0 м, значительно больше, чем в модели с заходкой 0,3 м, а зона распространения пластических деформаций почти в 2 раза выше. Детальный анализ результатов моделирования, позволил подтвердить возможность применения кольцевой монолитной бетонной крепи в подземных сооружениях.

Поскольку форма заглубленных сооружений зачастую отличается от круговой, то оценка НДС упрочняющейся бетонной крепи выработок некругового очертания в грунтовых массивах с низкими физико-механическими свойствами приобретает особую актуальность.

\section{Методы и материалы}

Анализируя ранее выполненные исследования для сооружений круговой формы [7], можно отметить, что через 18 часов после укладки бетона модифицированного добавкой Д5 за опалубку (в момент наибольших напряжений в крепи), его прочность превышала напряжения в 3 раза. Для состава модифицированного добавкой РЕЛАМИКС Т-2, коэффициент запаса по прочности не 
превышает 1,3. В этом случае требуется период времени до снятия опалубки не менее 24 часов. То есть при продолжительности проходческого цикла 12 часов и более, состав с добавкой РЕЛАМИКС T-2 может использоваться для возведения крепи круговой формы. Упругие характеристики бетонов определялись одновременно с испытаниями прочности на сжатие, что позволило на основе статистической обработки результатов исследования зависимости модуля упругости составов от их прочности получить уравнения регрессии [1]. Полученные результаты использованы для задания свойств изменяющейся во времени бетонной крепи.

Для оценки напряженно-деформированного состояния НДС крепи и массива грунта разработана методика моделирования подземных сооружений некругового очертания методом конечных элементов.

Целью моделирования является исследование распределения напряжений в крепи и грунтовом массиве, а также перемещений контура выработки в зависимости от механических характеристик грунта, параметров проведения и крепления сооружения, на основании которых необходимо разработать математическую модель для инженерных расчетов параметров проведения и крепления подземных сооружений, возводимых в неустойчивых грунтах.

Предварительная оценка НДС крепи подземных сооружений была выполнена для следующих форм: прямоугольной; сводчатой с прямоугольными стенками высотой 2,5 м; сводчатая с обратным сводом и прямоугольными стенками высотой 1,0 м. Для моделирования принимались средние значения определяющих факторов. В результате установлено, что выполнить расчет моделей прямоугольного и сводчатого со стенками высотой 2,5 м сечений не предоставляется возможным из-за их разрушения даже при средних значениях горного давления и механических свойств грунта. Поэтому дальнейшие исследования сооружений таких форм нецелесообразны.

Для расчетов принята пространственная модель изотропного массива грунта, с расположенной в нем выработкой со сводчатой 
крепью и с обратным сводом нагруженной горным давлением. Составление модели выполнено так, чтобы ось Z совпадала с продольной осью выработки, а оси X и Y соответственно с горизонтальной и вертикальной осями поперечного сечения.

Для упрощения сравнения напряжений и деформаций крепи и массива пород при составлении расчетного плана эксперимента, в качестве независимых факторов приняты: величина заходки - 1; величина давления на крепь - P; толщина крепи - h; сцепление грун$\mathrm{Ta}-\mathrm{C}_{\mathrm{r}}$; изменяющаяся во времени прочность бетона $-\mathrm{R}_{6}$. Уровни варьирования факторов в плане эксперимента приняты такими же, как и для подземных сооружений круглой формы.

Оценка НДС грунтового массива и крепи выполнена с применением мо-дели линейно-деформируемой среды, основанной на теории упругости, совместно с моделью разрушения, основанной на теории прочности Кулона-Мора.

В виду достаточно большого количества влияющих факторов число моделей, которые необходимо создать и рассчитать будет очень велико. Поэтому, с целью сокращения затрат времени для разработки регрессионной модели использована теория планирования эксперимента. При построении плана использован метод Брандона.

Реализация плана расчетного эксперимента, состоящего из 25 моделей, в каждой из которых 12 сечений с изменяющимися во времени характеристиками бетонной крепи, позволила выявить зоны и величины максимальных напряжений в крепи некругового очертания по мере удаления от забоя.

Подавляющее большинство подземных сооружений строящихся в наносных породах представленных глинистыми грунтами, суглинками и супесями, располагаются на глубине от 3 до 50 м. В этом случае величина горного давления, рассчитанная по специально разработанной методике, для исследуемой области будет находится в интервале от 0,2 МПа до 0,8 МПа.

Угол внутреннего трения пород может изменяться в пределах $10<\varphi<25$ градусов, а минимальное значение сцепления составляет 0,01-0,015 МПа. 
В сложных горно-геологических условиях толщина крепи должна быть не менее 0,3 м, и не более 0,5 м, так как большая толщина крепи нецелесообразна и связана с удорожанием строительства.

Для составления плана эксперимента выбраны равные интервалы изменения прочности бетона. В связи с этим область варьирования прочности выбиралась в зависимости от минимальных и максимальных значений прочности составов бетонов модифицированного добавкой РЕЛАМИКС Т-2. Время твердения принято от 6 до 72 часов с интервалом 6 часов. Диапазон значений величины заходки, установлен на уровне $0,3-0,7$ м.

Первоначально выполнялись расчеты моделей с величиной заходки 0,6-0,7 м. В результате установлено, что ряд моделей с неблагоприятными сочетаниями факторов (наибольшие значения горного давления и минимальные механические характеристики грунта), разрушались. Это потребовало корректировки плана эксперимента.

\section{Результаты исследований}

Результаты выполненного моделирования свидетельствуют о принципиальных отличиях распределения напряжений, как в сечении выработки, так и по ее продольной оси. Величины напряжений в наиболее характерных зонах сечений существенно отличаются.

В выработке круговой формы напряжения локализуются в боку на внутреннем контуре крепи (рис. 1б) и достигают максимума в третьей за-крепленной заходке. Это объясняется тем, что в третьей заходке модифицированный бетон в возрасте 18 часов перешел из пластичного состояния в твердое, и воспринимает нагрузки от горного давления. То есть, максимальные напряжения в крепи проявляются на расстоянии 0,9-2,8 м от забоя, в зависимости от величины заходки. В выработке некругового очертания максимальные напряжения имеют место в пяте свода и плавно возрастают по мере удаления от забоя и явно выраженного максимума и спада не имеют. 




Рис. 1. Распределение напряжений на внутреннем контуре крепи выработки: a - некругового очертания; б - круговой формы

На рисунке 2а приведено распределение напряжений в моделях кругового и некругового очертания при давлении 200 кПа на расстоянии 0,3 м, а на рисунке 26 на расстоянии 3,6 м от забоя, что соответствует времени твердения бетона 6 и 72 часа. Анализ показывает, что при удалении от забоя напряжения в крепи возрастают в несколько раз, но также растет и прочность бетона. Поэтому даже при глубине заложения выработки 50 м и величине заходки 0,7 м, прочность бетона превышает наряжения в 2,5 раза.
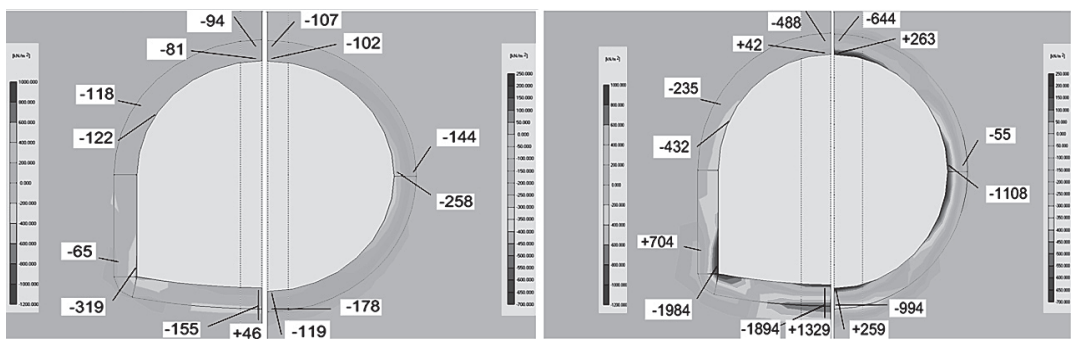

Рис. 2. Значения напряжений в различных зонах крепи выработки:

a - через 6 часов твердения бетона; б - через 72 часа твердения бетона

При моделировании проведена оценка деформаций в массиве грунта и поверхности над выработкой. Анализ результатов расчетов показывает, что максимальные смещения для рассматриваемых форм подземных сооружений наблюдаются в нетронутом 
массиве грунта на расстоянии $0,8-1,3$ м от забоя выработки и обусловлены формированием призмы сползания. Смещения грунта по плоскости забоя в выработку некругового очертания превышают деформации в выработку с кольцевой формой. Смещения в своде закрепленной части выработок кругового очертания также меньше.

На рисунке 3 приведено расчетное смещение поверхности по продольной оси выработки для модели с наиболее неблагоприятными сочетаниями управляемых факторов. Статистическая обработка результатов моделирования деформации дневной поверхности позволила установить наиболее значимые факторы и получить уравнение множественной регрессии (1) для определения максимально возможной осадки грунта над выработкой.

$$
\begin{gathered}
\Delta=-1170.79+\exp (7,08-0,01 l-0,02 P+ \\
\left.+0,002 h+0,11 C_{2}-0,02 R_{\sigma}\right)
\end{gathered}
$$

Величина достоверности аппроксимации приведенного уравнения регрессии составляет $\mathrm{R}^{2}=0,695$, а стандартная ошибка 3,11 .

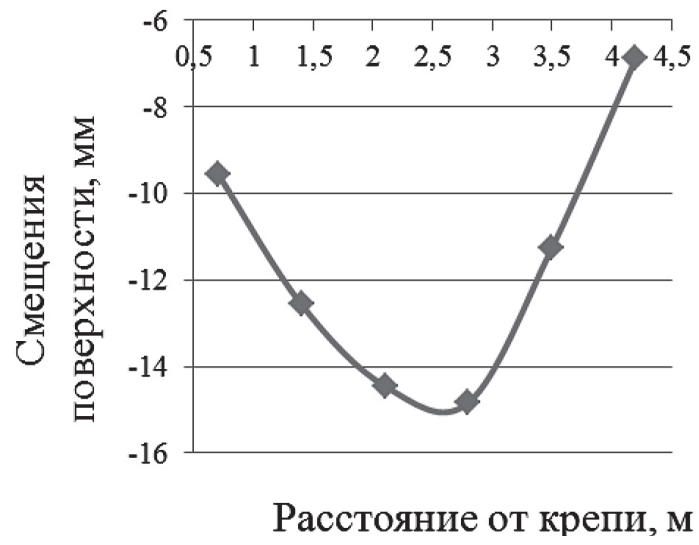

Рис. 3. Смещения поверхности над выработкой при: величине заходки $-0,7$ м; глубине заложения -50 м; коэффициенте сцепления грунта $-13,8$ кПа

Зона осадки поверхности массива в поперечном оси выработок направлении характеризуется плавным прогибом с максимальным значением на оси крепи (рис. 4). 


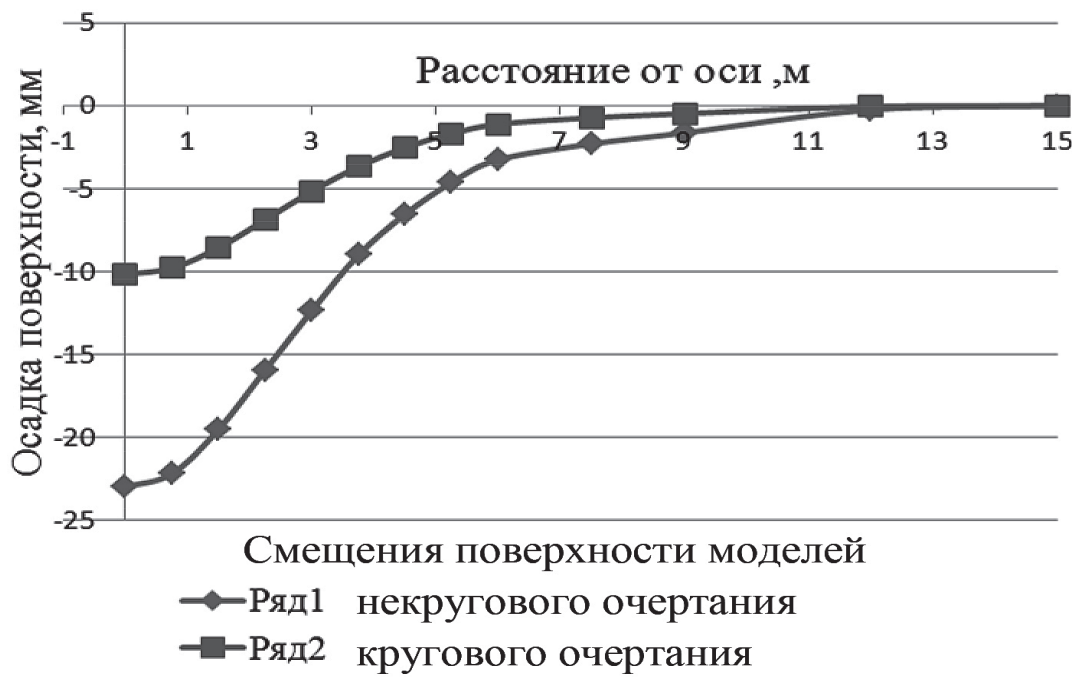

Рис. 4. Мульда смещений поверхности моделей при величине заходки 0,7 м и давлении 650 кПа

По результатам расчетов можно отметить, что в пределах факторного пространства смещения поверхности моделей не превышают 30 мм при конвергенции крепи 2,2 мм. При этом следует учитывать, что ввиду особенностей моделирования, смещения фиксировались на расстоянии 3 м от щелыги свода. Потому с увеличением глубины заложения выработок смещения поверхности будут еще меньше.

\section{Выводы}

Проведенные исследования позволили установить:

- максимальные сжимающие напряжения в крепи выработок некругового очертания локализуются в пяте обратного свода и при равных условиях более чем в 1,5 раза больше чем в кольцевой крепи;

- растягивающие напряжения локализуются в средней части обратного свода и близки к прочностным характеристикам бетона, поэтому требуется расчет напряженного состояния крепи от растягивающих напряжений; 
- по результатам моделирования установлено, что осадка поверхности при креплении монолитным бетоном значительно меньше, чем при сборной крепи;

- в пределах факторного пространства крепь некругового очертания на всех этапах твердения бетона сохраняет работоспособность, что свидетельствует о возможности применения технологии проходки короткими заходками.

Исследование выполнено при финансовой поддержке РФФИ в рамках научного проекта № 16-35-00328 мол_а.

\section{Список литературы}

1. Левченко А.Н. Геотехнологическая стратегия и высокие технологии освоения подземного пространства города Москвы // Горный информационно-аналитический бюллетень (научно-технический журнал). 2006. С. 14-18.

2. Теличенко В.И., Зерцалов М.Г., Конюхов Д.С. Состояние и перспективы освоения подземного пространства г. Москвы // Вестник МГСУ. 2010. Т. 4. № 4. С. 24-36.

3. Беляев В.Л. Планирование градостроительного освоения подземного пространства г. Москвы // Вестник МГСУ, 2013, № 1. C. 35-46.

4. Строкова Л.А. Моделирование оседания поверхности при проходке туннеля щитовым способом // Известия Томского политехнического университета. 2008. Т. 312. № 1. С. 45-50.

5. Павленко А.М. Предотвращение сдвижений дневной поверхности при проходке тоннеля большого диаметра // Горный информационно-аналитический бюллетень. 2008. №9. С. 170-173.

6. Киреева В.И. Мониторинг деформаций с помощью роботизированного тахеометра Trimble серии S / В.И. Киреева, А.А. Смирнова // Маркшейдерско-геодезическое обеспечение рационального использования, охраны недр и строительства сооружений: межвуз. сб. науч. тр. / Юж.-Рос. гос. политехн. ун-т (НПИ). Новочеркасск: ЮРГПУ (НПИ). 2012. С. 100-106. 
7. Bauer M.A., Dmitrienko V.A., Kapustin A.I. Assessment of Deformations of Earth's Surface at Mine Construction on Sub-SoilsOriginal Research Article. Procedia Engineering, Volume 150, 2016, Pages 22782286, 2nd International Conference on Industrial Engineering (ICIE2016) https://mail.rambler.ru/m/redirect?url=http $\% 3 \mathrm{~A} / / \mathrm{www}$.sciencedirect.com/science/article/pii/S1877705816316204\&hash=29279a60deb49a8e63b6f093921ad51d

8. Плешко М.С., Крошнев Д.В. Влияние свойств твердеющего бетона на взаимодействие системы «крепь - массив» в призабойной зоне ствола // Горный информационно-аналитический бюллетень. 2008. №9. С. 320-325.

9. Масленников С.А., Прокопов А.Ю., Шинкарь Д.И. К вопросу о влиянии технологических факторов на деформационные характеристики бетона в многослойной крепи // Научное обозрение. №11. М.: МГГУ, 2013. С. 97-102.

10. Stradanchenko S., Maslennikov S., Dmitrienko V., Kokun'ko I., Kapralova I. Prospects of mining waste use // Metallurgical and Mining Industry 7 (10), pp. 208-212. http://www.scopus.com/authid/detail.uri?origin=resultslist\&authorId $=564953174004$.

11. Maslennikov S., Dmitrienko V., Kokunko I., Dmitrienko N. Investigating the micro silica effect on the concrete strength: MATEC Web of Conferences 106, 03025, 2017. URL: https://www.matec-conferences.org/ articles/matecconf/pdf/2017/20/matecconf_spbw2017_03025.pdf

12. Бауэр М.А., Дмитриенко В.А. Результаты исследований механических свойств быстротвердеющих модифицированных бетонов // Инженерный вестник Дона. 2016. T. 43. № 4. URL: http://www. ivdon.ru/ru/magazine/archive/n4y2016/3916

13. Прокопов, А.Ю. Изучение напряженно-деформированного состояния грунтового массива и взаимного влияния подземных конструкций существующих и вновь возводимых сооружений в береговой зоне морского порта Тамань [Электронный ресурс] / А.Ю. Прокопов, В.Ф. Акопян, К.Н. Гаптлисламова // Инженерный вестник Дона. 2013. №4. URL: http://www.ivdon.ru/magazine/ archive/n4y2013/2104 
14. Масленников С.А., Долуглу Т.А., Яковлева К.С. Моделирование подпорной стены насыпи методом конечных элементов // Инженерный вестник Дона, 2015, №3. URL: http:/www.ivdon.ru/ru/magazine/ archive/n3y2015/3263

15. Дмитриенко В.А., Дулоглу Т.А., Масленников С.А. Оценка устойчивости откосов насыпи. В книге: Строительство и архитектура 2015 материалы международной научно-практической конференции. ФГБОУ ВПО «Ростовский государственный строительный университет», Союз строителей южного федерального округа, Ассоциация строителей Дона. 2015. С. 434-437.

16.Zafirovski Z. Analysis of stress-deformation state in the rock massif using Z-SOIL program: MATEC Web of Conferences, Volume 53, 2016. URL: https://doi.org/10.1051/matecconf/20165301028

17. Chernysheva N., Rozin L. Modified finite element analysis for exterior boundary problems in infinite medium: MATEC Web of Conferences, Volume 53, 2016. URL: https://doi.org/10.1051/matecconf/20165301042

\section{References}

1. Levchenko A.N. Gornyy informatsionno-analiticheskiy byulleten'. 2006, pp. 14-18.

2. Telichenko V.I., Zertsalov M.G., Konyukhov D.S. Vestnik MGSU. 2010. V. 4. № 4, pp. 24-36.

3. Belyaev V.L. Vestnik MGSU, 2013, № 1. S. 35-46.

4. Strokova L.A. Izvestiya Tomskogo politekhnicheskogo universiteta. 2008. V. 312. № 1, pp. 45-50.

5. Pavlenko A.M. Gornyy informatsionno-analiticheskiy byulleten'. 2008. №9, pp. 170-173.

6. Kireeva V.I., Smirnova A.A. Marksheydersko-geodezicheskoe obespechenie ratsional'nogo ispol'zovaniya, okhrany nedr i stroitel'stva sooruzheniy : mezhvuz. sb. nauch. tr. [Markshay-dersko-geodeticheskoye maintenance of rational use, protection of bowels and construction of structures: interuniversity]. Novocherkassk: YuRGPU (NPI). 2012, pp. 100-106.

7. Bauer M.A., Dmitrienko V.A., Kapustin A.I. Assessment of Deformations of Earth`s Surface at Mine Construction on Sub-SoilsOriginal Research 
Article. Procedia Engineering, Volume 150, 2016, Pages 2278-2286, 2nd International Conference on Industrial Engineering (ICIE-2016) $\mathrm{https}: / /$ mail.rambler.ru/m/redirect?url $=\mathrm{http} \% 3 \mathrm{~A} / / \mathrm{www}$.sciencedirect. $\mathrm{com} / \mathrm{science} / \mathrm{article} / \mathrm{pii} / \mathrm{S} 1877705816316204 \&$ hash$=29279 \mathrm{a} 60 \mathrm{de}-$ b49a8e63b6f093921ad51d

8. Pleshko M.S., Kroshnev D.V. Gornyy informatsionno-analiticheskiy byulleten’. 2008. №9, pp. 320-325.

9. Maslennikov S.A., Prokopov A.Yu., Shinkar' D.I. Nauchnoe obozrenie. №11. M.: MGGU, 2013, pp. 97-102.

10. Stradanchenko S., Maslennikov S., Dmitrienko V., Kokun'ko I., Kapralova I. Prospects of mining waste use. Metallurgical and Mining Industry 7 (10), pp. 208-212. http://www.scopus.com/authid/detail.uri?origin=resultslist\&authorId $=564953174004$.

11. Maslennikov S., Dmitrienko V., Kokunko I., Dmitrienko N. Investigating the micro silica effect on the concrete strength: MATEC Web of Conferences 106, 03025, 2017. https://www.matec-conferences.org/ articles/matecconf/pdf/2017/20/matecconf_spbw2017_03025.pdf

12. Bauer M.A., Dmitrienko V.A. Inzhenernyy vestnik Dona. 2016. V. 43. № 4. http://www.ivdon.ru/ru/magazine/archive/n4y2016/3916

13. Prokopov A.Yu., Akopyan V.F., Gaptlislamova K.N. Inzhenernyy vestnik Dona. 2013. №4. http://www.ivdon.ru/magazine/archive/n4y2013/2104 14. Maslennikov S.A., Doluglu T.A., Yakovleva K.S. Inzhenernyy vestnik Dona, 2015, №3. URL: http://www.ivdon.ru/ru/magazine/archive/ n3y2015/3263

15. Dmitrienko V.A., Duloglu T.A., Maslennikov S.A. Stroitel'stvo i arkhitektura - 2015 materialy mezhdunarodnoy nauchno-prakticheskoy konferentsii [Construction and Architecture - 2015 materials of the international scientific and practical conference]. 2015, pp. 434-437.

16. Zafirovski Z. Analysis of stress-deformation state in the rock massif using Z-SOIL program: MATEC Web of Conferences, Volume 53, 2016. https://doi.org/10.1051/matecconf/20165301028

17. Chernysheva N., Rozin L. Modified finite element analysis for exterior boundary problems in infinite medium: MATEC Web of Conferences, Volume 53, 2016. URL: https://doi.org/10.1051/matecconf/20165301042 


\section{ДАННЫЕ ОБ АВТОРЕ}

Бауэр Мария Александровна, преподаватель Политехнического колледжа, кандидат технических наук

Шахтинский Институт (филиал) Южно-Российского государственного политехнического университета (Новочеркасский Политехнический Институт) им. М.И. Платова пл. Ленина, 1, г. Шахты, Ростовская область, 346500, Российская Федерация bauer_npi@mail.ru

\section{DATA ABOUT THE AUTHOR}

Bauer Maria Aleksandrovna, Teacher of the Polytechnic College, Candidate of Technical Sciences

Shakhtinsky Institute (branch) of the South-Russian State Polytechnic University (Novocherkassk Polytechnic Institute)

1, pl. Lenin, Shakhty, Rostov Region, 346500, Russian Federation bauer_npi@mail.ru 